\title{
Anaplastic thyroid carcinoma
}

INSERM

\section{Source}

INSERM. (1999). Orphanet: an online rare disease and orphan drug data base. Anaplastic thyroid carcinoma. ORPHA:142

Anaplastic thyroid carcinoma may represent the ultimate dedifferentiation step of thyroid tumorigenesis and is one of the most severe cancers in humans. 